\title{
Clarifications of a Datum Axis or Centerplane Specifying in Maximum Ma- terial Condition of Geometric Dimensioning and Tolerancing
}

\author{
Dr. Cheng Y. Lin P.E., Old Dominion University
}

Dr. Lin is a professor and program director of Mechanical Engineering Technology at Old Dominion University. He received his Ph.D. of Mechanical Engineering from Texas A\&M University in 1989, and is a registered professional engineer in Virginia. Dr. Lin has expertise in automation control, machine design, CAD/CAM, CNC, geometric dimensioning and tolerancing, and robotics. He has published sixteen journal papers in the areas of robotics, automation, and GD\&T. He has been active in the technology application research and teaching training courses for Virginia's Applied Technology and Professional Development Center (VATPDC).

\section{Dr. Jennifer Grimsley Michaeli P.E., Old Dominion University}

Dr. Jennifer Michaeli is an assistant professor in the Mechanical Engineering Technology Program at the Department of Engineering Technology of Old Dominion University. She received her Ph.D. in Mechanical Engineering from Old Dominion University, her M.Sc. in Ocean Systems Management from Massachusetts Institute of Technology, and her B.Sc. in Naval Architecture and Marine Engineering from Webb Institute. Dr. Michaeli has over fifteen years practical work experience in the government and private industry as a Naval Architect and program manager where she oversaw the design, construction and testing of a wide range of high performance marine vehicles and associated technologies for the United States and foreign navies. Dr. Michaeli has expertise in the design, construction, testing and fielding of advanced combatant vessels and associated technologies. She has taught courses in Engineering, Naval Architecture, and Computer Aided Design. Dr. Michaeli is a past recipient of the ASNE Rosenblatt Young Engineer of the Year Award and the U.S. Navy's ADM Melville Award. She is a registered professional engineer in Virginia. She is a member of ASEE, ASNE, RINA, and SNAME.

\section{Prof. Mileta Tomovic, Old Dominion University}

Dr. Tomovic is serving as the chair of Engineering Technology Department, Old Dominion University, Norfolk, Va. Prior to joining ODU Dr. Tomovic was faculty member at Purdue University, West Lafayette, Indiana. While at Purdue University, Dr. Tomovic held the position of W. C. Furnas chaired professor at the College of Technology. He also served as special assistant to the dean for Advanced Manufacturing, co-director for Product Lifecycle Management Center of Excellence, director of Digital Enterprise Center, and department head of Mechanical Engineering Technology Department. Dr. Tomovic is also Honorary Professor at Beihang University, Beijing, China. Dr. Tomovic received B.S. in Mechanical Engineering from the University of Belgrade, Yugoslavia, M.S. in Mechanical Engineering from the Massachusetts Institute of Technology, and Ph.D. in Mechanical Engineering from the University of Michigan. Dr. Tomovic co-authored one textbook on materials and manufacturing processes that has been adopted by over 50 national and international institutions of higher education. In addition, he has authored or co-authored over 60 papers in journals and conference proceedings, focused on applied research related to product lifecycle management, design and manufacturability, system dynamics and controls, and engineering education. Dr. Tomovic delivered over 20 invited presentations nationally and internationally. He has authored and/or co-authored four patents, and over 100 technical reports on practical industrial problems related to product design and manufacturing process improvements. 


\title{
Geometric Dimensioning and Tolerancing: Clarifications on Specifying a Maximum Material Condition Datum Axis or Center Plane
}

\begin{abstract}
Engineering and Engineering Technology students and professionals learning the processes and standards in computer-aided design (CAD) and computer-aided manufacturing (CAM) should learn and understand the methodology of geometric dimensioning and tolerancing (GD\&T) to describe the intent and requirements for part and assembly geometries. Correct application of GD\&T ensures that the part and assembly geometry defined on the drawing will have the desired form and fit (within limits) and function as intended. One learning difficulty in understanding GD\&T is the concept of defining a datum axis or center plane using Maximum Material Condition (MMC). To overcome this difficulty, a new approach is presented that uses a modifier "(V)" (Virtual Condition) instead of "(M)" (MMC). A thorough rationalization of using "(V)" in datum axis specification is discussed. The paper also provides a convenient table on how to use this modifier.
\end{abstract}

\section{Introduction}

Geometric dimensioning and tolerancing (GD\&T) is a quality control method using a symbolic language that allows design engineers, manufacturing personnel, and quality inspectors to describe geometry and allowable variation of parts and assemblies in an efficient and effective manner ${ }^{1}$. GD\&T is used to define the theoretically perfect geometry of parts and assemblies, to define the allowable variation of individual features (e.g., surfaces, holes), and to define the allowable variation between features. When compared to coordinate dimensioning, GD\&T has the benefits of reducing the manufacturing cost and number of drawing revisions, describing an important functional relationship on a part, saving inspection time by using functional gages, and improving measurement repeatability ${ }^{2,3}$.

GD\&T has been widely accepted in manufacturing, both in the United States and internationally, and as such has been included in curricula focused on developing engineering and manufacturing drawings. However, GD\&T has a fairly complex rule-based system, and as a result can be difficult to teach and learn. Several papers have been published to explain various aspects of the GD\&T methodology and to improve the student's learning performance ${ }^{4,5,6,7,8}$. Unlike existing papers that have published to bring clarity to the difficult subject of GD\&T, this paper examines the challenges in defining a datum axis or center plane using Maximum Material Condition (MMC) and provides a clarification approach using Virtual Condition (VC).

\section{Datum References}

Datum references, such as a datum axis or center plane, play a key role in achieving the advantages of the GD\&T methodology. A datum reference is defined as a theoretically exact 
plane, edge, point, or axis from which a dimensional measurement is made (Krulikowski, 1998, 2012). Figure 1 shows a GD\&T drawing using three planar features as datum references: A, B, and C. Here Datums A, B, and C are known as the primary datum, secondary datum, and tertiary datum respectively.

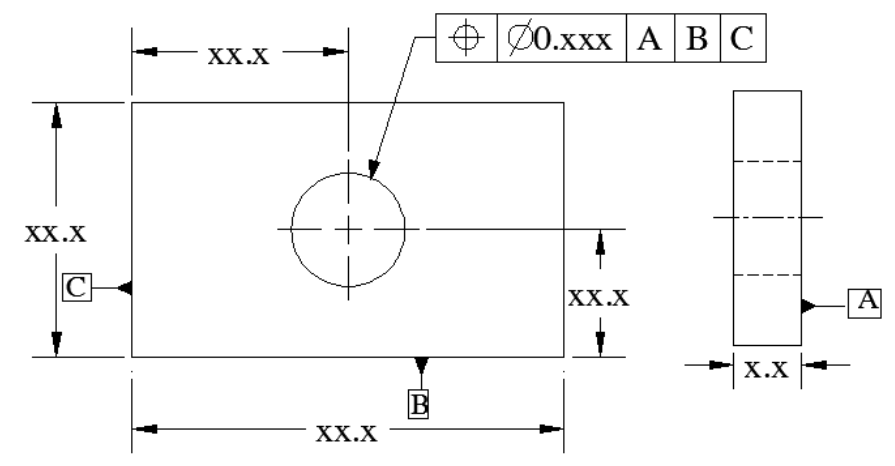

Figure 1: Three Planar Datums

Figure 2 shows another drawing using a feature of size (FOS) as a datum reference. A FOS is defined as a cylindrical surface, spherical surface, or two opposed parallel elements or surfaces that can be associated with a size dimension. When a FOS is specified as a datum feature, it results in an axis or a center plane as a datum. In Figure 2 the datum feature is defined as the center axis of the drilled hole.

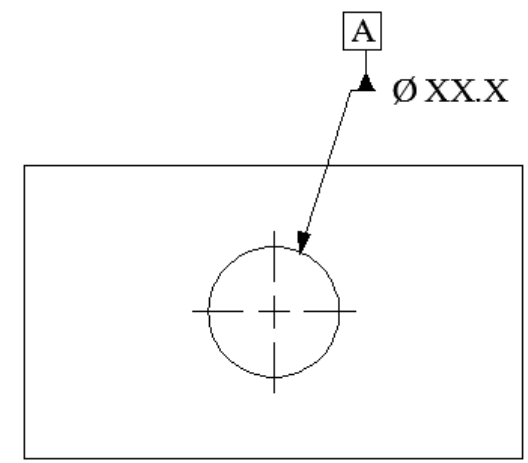

Figure 2: A Feature-of-Size (FOS) Datum

While many datum references can be been clearly defined, students and professionals have experienced learning difficulties in correctly defining an MMC datum axis. MMC, VC, and an approach to resolve difficulties with MMC datum axis are discussed below.

\section{Maximum Material Condition (MMC)}

Maximum Material Condition (MMC) refers to the condition when a FOS contains the maximum amount of material, yet remains within its stated limits of $s^{2} e^{2,3}$. The MMC for an external FOS (e.g., shaft diameter or outer sizes of an object) is the largest value of the basic dimension and tolerance. The MMC for an internal FOS (e.g., hole diameter) is the smallest 
value of the basic dimension and tolerance. Figure 3 shows an example of MMC for both internal and external FOS.

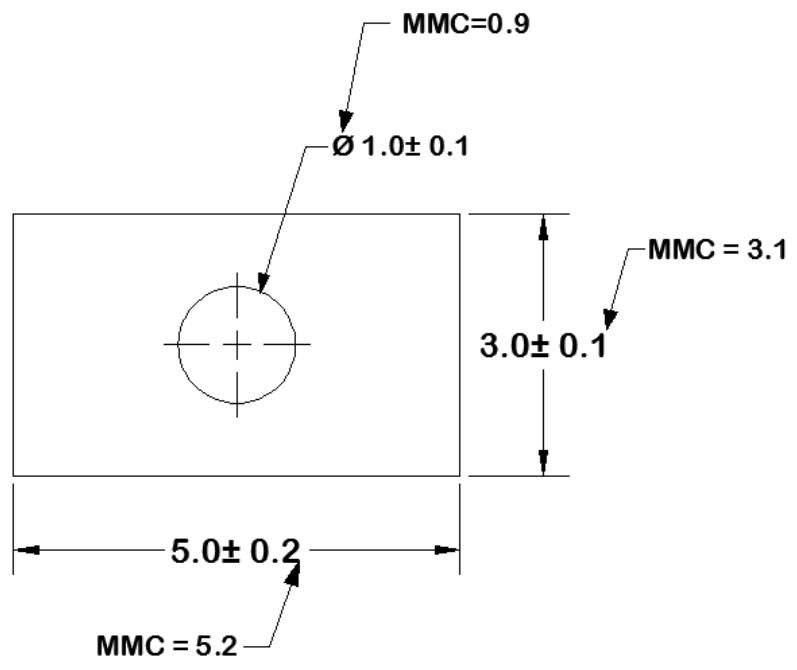

Figure 3: Specifying MMC for External and Internal Features

\section{Virtual Condition (VC)}

Virtual Condition is the theoretical extreme boundary condition of a FOS generated by the collective effects of MMC and any other applicable geometric tolerances ${ }^{2,3}$. Virtual condition is used by designers to analyze mating parts, by gauge manufactures to find the gauge dimensions and by inspectors to check extreme conditions. Figures 4 and 5 give examples of VC calculations for both external and internal FOS.

In Figure 4, when a GD\&T tolerance is not applied to an external feature, VC is equal to the MMC (largest size) of the material. However, when a GD\&T tolerance is applied to the FOS, $V C$ $=M M C+G D \& T$ Tolerance.

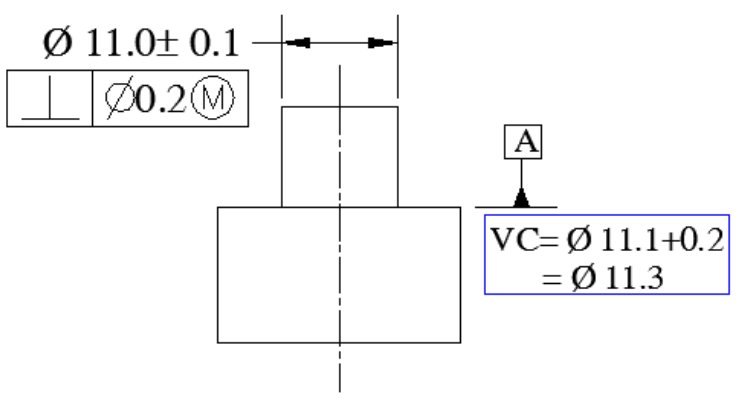

Figure 4: VC for an External Feature

In Figure 5, when a GD\&T tolerance is applied to an internal feature, VC is equal to the MMC (smallest size) of the material. However, when a GD\&T tolerance is applied to the FOS, $V C=$ $M M C-G D \& T$ Tolerance. 


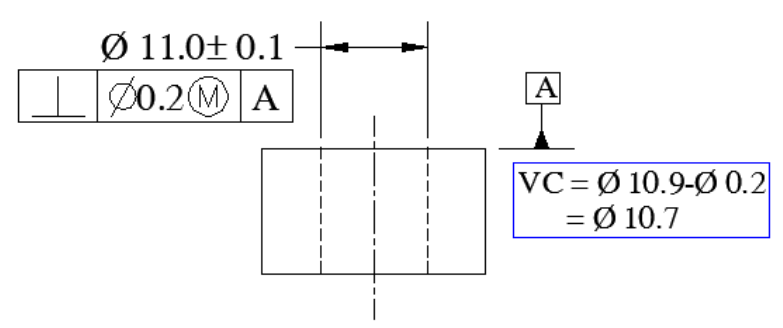

Figure 5: VC for an Internal Feature

\section{MMC Datum Axis}

When a FOS is used as a datum reference, an adjustable gage element is needed to simulate the geometric counterpart of the datum feature. The gage element is also used to orient and secure the part. When the FOS datum is referenced at MMC, the gaging equipment that serves as the datum feature simulator is a fixed size ${ }^{2}$. The datum axis or centerplane is the axis or centerplane of the gauge element. Figure 6 shows a datum axis specified as "A®M" (MMC). Since the MMC of the FOS is $\varnothing 2.0050 "$ ", the fixed gage size which defines the datum axis is easily understood to be $\varnothing 2.0050 "$ " (showing on the very right side of Figure 6).
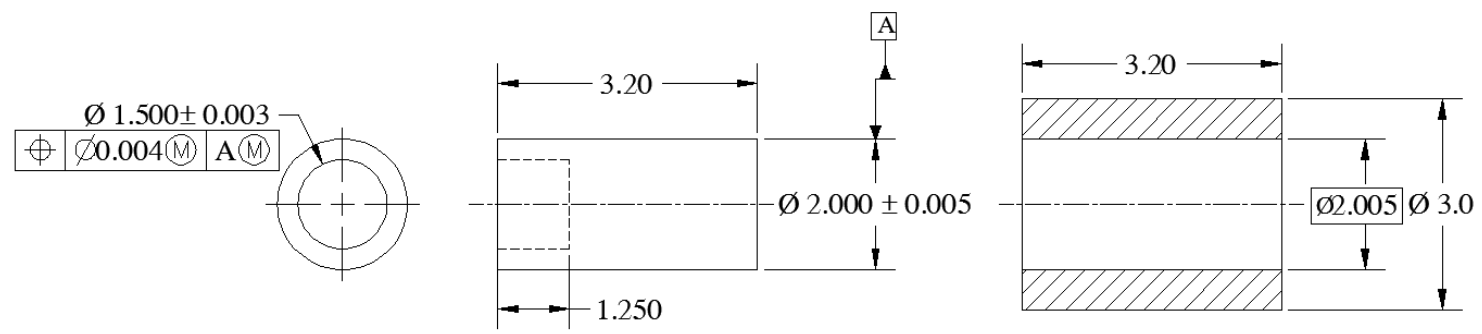

Figure 6: Datum Axis Using A $\mathbb{M}$ to Define the Datum Axis

However, the datum axis " $\mathrm{A}(\mathbb{M})$ " specified in Figure 7 causes a problem to students. The gage size for this datum axis is equal to $\varnothing 2.0070 "$ ", the VC of the external feature. While the $\mathbb{M}$ ) symbol can be interpreted as VC for MMC in the ASME Y14.5M $-1994^{2}$ or as Maximum Material Boundary (MMB) in the ASME Y14.5M $-2009^{3}$, the $\mathbb{M}$ symbol is commonly recognized as MMC for the FOS. This ambiguity introduces uncertainty and frustration to students that are learning to master the rules and methodology of GD\&T.

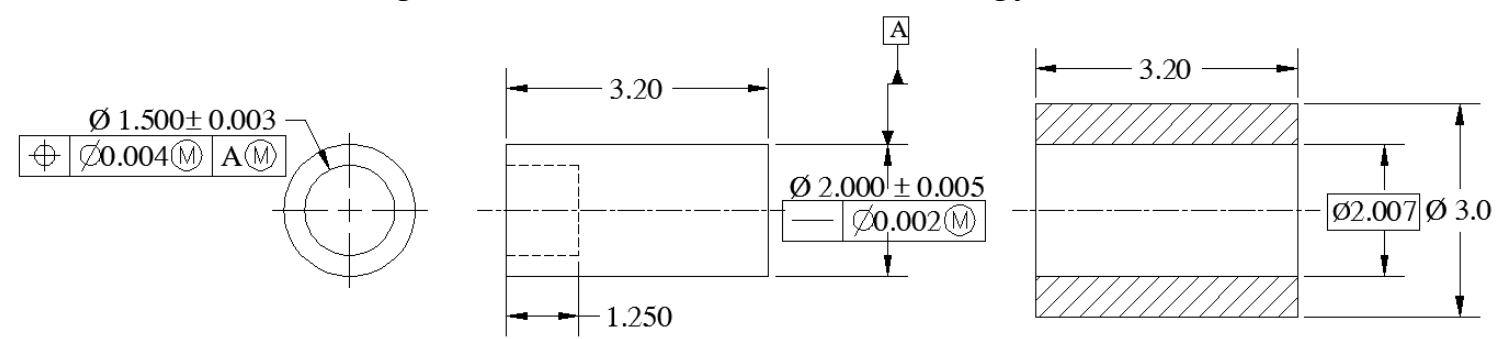

Figure 7: Datum Axis Associated with a GD\&T Tolerance to Define the Datum Axis 
To avoid this confusion, and to clarify an important aspect in the learning process for GD\&T curricula, the authors propose that a new modifier symbol, (V), referring to the Virual Condition (VC) be used. This new modifier symbol $(\mathrm{V})$ is used to replace $\mathbb{M}$, when both the MMC and geometric tolerance are necessary to fully describe the part feature, as shown in Figure 8. Note, the use of the new modifier (V) can only be applied to define a center axis or center plane when an $(M)$ is used in the geometric tolerance associated with the datum.
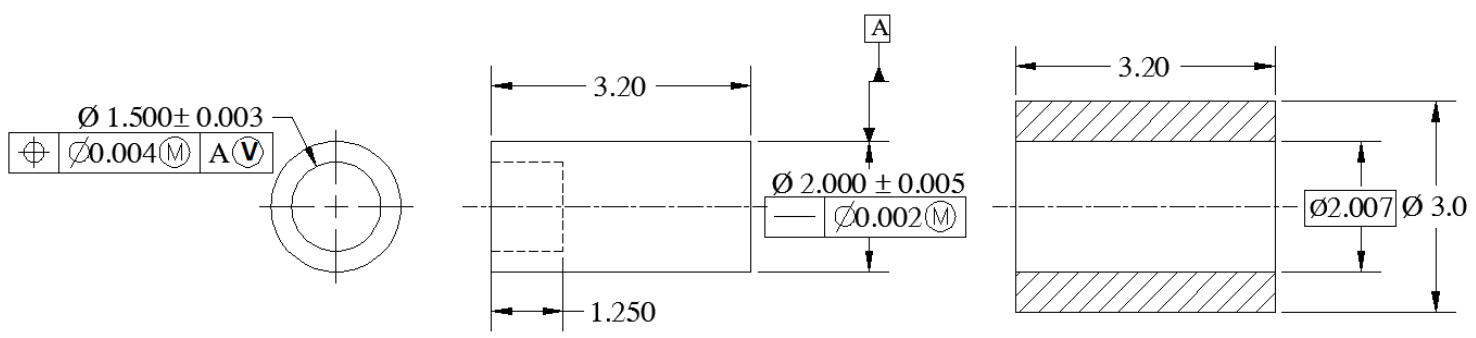

Figure 8: Approach using New Modifier (V) to Replace the Part Showing in Figure 7

Table 1 provides convenient guidance regarding how the new modifier $\nabla$ in specifying a datum axis and center plane for MMC is intended to clarify this procedure in GD\&T.

Table 1: Proposed Definitions for Datum Axis

\begin{tabular}{|c|c|c|c|}
\hline Modifier Used in & No Modifier & Modifier (M) & Modifier (V) \\
\hline $\begin{array}{l}\text { Defining the } \\
\text { Datum Axis }\end{array}$ & \begin{tabular}{|l|l|l|} 
कxx & A \\
\end{tabular} & \begin{tabular}{|l|l|l|}
$\phi x x$ & A \\
\end{tabular} & \begin{tabular}{|l|l|l|}
$\phi x x$ & $A \otimes$ \\
\end{tabular} \\
\hline $\begin{array}{l}\text { Definition of the } \\
\text { Datum Axis }\end{array}$ & $\begin{array}{l}\text { Regardless of Feature } \\
\text { of Size }^{1} \text { (RFS) or } \\
\text { Regardless of } \\
\text { Material Boundary } \\
\text { (RMB) }\end{array}$ & $\begin{array}{l}\text { No GD\&T Tolerance } \\
\text { Specified in } \\
\text { Defining Datum A }\end{array}$ & $\begin{array}{l}\text { (M) Used in the } \\
\text { GD\&T Tolerance } \\
\text { In Defining Datum } \\
\text { A }\end{array}$ \\
\hline
\end{tabular}

The authors have recently introduced this new approach to the classroom. Students were surveyed on their understanding of specifying a datum axis or center plane. Students agreed that this will certainly clarify the issues in specifying a datum axis or center plane. A group of fifty one students (including 31 undergraduate seniors and 20 industrial engineers) have been asked the same question using original definition and new approach; the later improved the test performance from $65 \%$ to $91 \%$. As this was a small class size, the authors plan to integrate this approach into the classroom for several semesters and evaluate the impact it has in the learning process.

\section{Summary}


The use of a modifier ( $\mathrm{V}$ in defining a datum axis is proposed to clarify a datum axis when an $(\mathrm{M})$ is used in the geometric tolerance associated with the datum. As VC has been clearly defined, students will have no difficulty calculating the fixed gage size for the datum axis. Students can be guided to use Table 1 in defining the datum axis. However, as $(\mathrm{V})$ is not adopted in the current standards, instructors can emphasize the meaning of what $(\mathrm{M})$ really represents in the current standards when an MMC GD\&T tolerance is specified with the datum.

\section{Bibliography}

1. Hewerdine, K. Leake, J. Brent, H., June, 2011, "Linking CAD and Metrology to Explain, Demonstrate, and Teach Geometric Dimensioning and Tolerancing" 118th ASEE Annual Conference and Exposition.

2. Krulikowski, A., 1998, "Fundamentals of Geometric Dimensioning and Tolerancing", $2^{\text {nd }}$ Edition, Delmar.

3. Krulikowski, A., 2012, "Fundamentals of Geometric Dimensioning and Tolerancing", $3^{\text {rd }}$ Edition, Delmar.

4. Yang, D., Gong, J., 2010, "Comprehensive Tolerancing System for 3D Mechanical Assemblies", Advanced Materials Research, V 139-141.

5. Lin, C., Verma, A., 2009, “Applicability of Rule 2 in Geometric Dimensioning and Tolerancing”, Journal of Engineering Technology, pp. 16-22.

6. Lin, C., Luetke, N., 2011, "Calculation of Tolerance Stacks Using Direct-Position Approach in Geometric Dimensioning and Tolerancing", Journal of Engineering Technology, pp. 10-14.

7. Wu, Y., Davidson, J., March 2003, “Computer Modeling of Geometric Variations in Mechanical Parts and Assemblies", Transactions of the ASME. Journal of Computing and Information Science in Engineering, v 3, n 1, 54-63.

8. Pandya, G., Lehtihet, E., Cavalier, T., March 2002, “Tolerance Design of Datum Systems”, International Journal of Production Research, v 40, n 4, 783-807. 